\title{
AVALIAÇÃO TECNOLÓGICA DA EXTRAÇÃO ALCOÓLICA NO PROCESSAMENTO DE LICOR DE BANANA
}

\author{
LUCIANO JOSÉ QUINTÃO TEIXEIRA* \\ AFONSO MOTA RAMOS** \\ JOSÉ BENÍCIO PAES CHAVES*** \\ PAULO HENRIQUE ALVES DA SILVA**** \\ PAULO CÉSAR STRINGHETA*****
}

\begin{abstract}
Neste trabalho objetivou-se estabelecer a proporção de banana, a composição da solução extratora, bem como o tempo de extração para produzir licor com qualidade. Efetuou-se experimento fatorial com três quantidades de polpa de banana (500, 800 e $1100 \mathrm{~g}$ de banana para produção de $4 \mathrm{~L}$ de licor) e dois teores alcoólicos da solução extratora $\left(70\right.$ e $\left.95^{\circ} \mathrm{GL}\right)$. O processo de extração foi estudado durante 21 dias em que se analisaram as coordenadas de cor, $\mathrm{pH}$, teor de sólidos solúveis e densidade a $20^{\circ} \mathrm{C}$ do extrato. O licor jovem foi caracterizado e submetido à análise sensorial após 45 dias de envelhecimento. $O$ tempo de 16 dias mostrou-se suficiente para finalizar a etapa de extração, evidenciando que o tempo de infusão deve ser de 15 a 16 dias. A solução extratora com teor alcoólico de $95^{\circ} \mathrm{GL}$ apresentou melhores resultados, principalmente no que se refere à cor final do produto e facilidade na filtração. Como não houve diferença significativa entre as quantidades de polpa de banana optouse pela menor proporção em razão de fatores econômicos. Portanto, a utilização de $500 \mathrm{~g}$ de polpa de banana é suficiente para produzir $4 \mathrm{~L}$ de licor.
\end{abstract}

PALAVRAS-CHAVE: LICOR DE BANANA - PROCESSAMENTO; LICOR DE BANANA - ANÁLISES FÍSICO-QUÍMICAS; ANÁLISE SENSORIAL.

* $\quad$ Engenheiro de alimentos, Doutorando em Ciência e Tecnologia de Alimentos Universidade Federal de Viçosa (UFV), Viçosa - MG (e-mail: luqteixeira@yahoo.com.br).

** Professor adjunto do Departamento de Tecnologia de Alimentos, UFV (e-mail: amramos@ufv.br).

*** Professor titular do Departamento de Tecnologia de Alimentos, UFV (e-mail: jbchaves@ufv.br).

**** Professor adjunto do Departamento de Tecnologia de Alimentos, UFV (e-mail: phsilva@ufv.br).

***** Professor titular do Departamento de Tecnologia de Alimentos, UFV (e-mail: stringap@ufv.br). 


\section{INTRODUÇÃO}

As bebidas alcoólicas sempre ocuparam lugar de destaque nas mais diversas civilizações. Essas são classificadas segundo a legislação brasileira em fermentadas (cerveja e vinho), por misturas (licor, amargo e aperitivo, aguardentes compostas e bebidas mistas), destiladas (cachaça, rum, aguardente, uísque e conhaque) e destilo-retificadas (vodca e gim) (AQUARONE, LIMA e BORZANI, 1993).

Os licores podem ser definidos como destilados alcoólicos que foram adoçados e aromatizados com substâncias e sabores compatíveis. Também é possível adicionar corantes e alguns edulcorantes. Os licores tradicionais são elaborados pela mistura de destilado com xarope de açúcar que contém essências e ervas em pequenas quantidades (VARNAM e SUTHELAND, 1994). Licor, segundo a legislação brasileira, é a bebida com graduação alcoólica de quinze a cinqüenta e quatro por cento em volume, a vinte graus Celsius, com percentual de açúcar superior a trinta gramas por litro. É elaborada com álcool etílico potável de origem agrícola, ou destilado alcoólico simples de origem agrícola, ou com bebida alcoólica, adicionada de extratos ou substâncias de origem vegetal ou animal, substâncias aromatizantes, saborizantes, corantes e outros aditivos permitidos em ato administrativo complementar (BRASIL, 1997).

A produção artesanal de licores constitui alternativa interessante para proporcionar aumento da renda familiar, pois seu processamento exige tecnologia simples, o produto final é comercializado em temperatura ambiente e apresenta extensa vida-de-prateleira.

Segundo REVENTOS (1971) existem basicamente dois processos para fabricação de licor (por destilação e por misturas). O processo por destilação consiste em colocar a matéria-prima em contato com álcool ou com água por algumas horas, seguida de destilação. Misturando o destilado com o xarope obtém-se o licor. Esse processo é mais comum na fabricação de licores a partir de sementes (destilação alcoólica) e rosa (destilação aquosa). Os licores por misturas (sem destilação) são subdivididos em licores obtidos por infusão e por essência. Os licores naturais (produzidos de frutas) são fabricados normalmente pelo método da infusão que consiste em deixar a fruta em infusão numa solução hidroalcoólica (água e álcool) por determinado período, seguido de filtração e adição de xarope. O licor produzido por essência não passa pela etapa de infusão, ocorrendo simplesmente a mistura da essência, do álcool e do xarope. Esse é o caso de alguns licores comerciais e daqueles cuja 
matéria-prima não propicia o processo de infusão como os licores de chocolate, cacau, leite, etc. O tempo de infusão das frutas, ou seja, o tempo em que deve permanecer em contato com o álcool varia de fruta para fruta. A literatura recomenda 15 dias para a banana, 3 dias para a jabuticaba e 2 meses para a laranja, porém não se encontra estudo que estabeleça o melhor tempo de extração para as frutas citadas.

As etapas da elaboração de licores de frutas envolvem infusão, preparo do xarope, mistura, envelhecimento, clarificação, filtração e envase (BORGES, 1975). A qualidade do licor dependerá da formulação utilizada, do emprego de boas práticas de fabricação e do processamento.

Objetivou-se com este estudo investigar a proporção adequada de banana para se produzir licor com qualidade, a composição da solução extratora, bem como o tempo necessário para que se processe a extração dos compostos da banana que vão conferir corpo, cor, sabor e aroma ao licor.

\section{MATERIAL E MÉTODOS}

O licor de banana foi preparado a partir de purê de banana nanica, acidificado com ácido cítrico e ácido ascórbico, submetido a tratamento térmico por 2 minutos a $94^{\circ} \mathrm{C}$, conforme recomendado em BANANA... (1995) e por MATSUURA E FOLEGATTF (2001). As bananas descascadas foram submergidas em solução com $4 \%$ de ácido cítrico e $1 \%$ de ácido ascórbico pelo período de 5 minutos, trituradas e submetidas ao tratamento térmico.

Foram utilizados álcool de cereais, açúcar refinado e água potável em proporções adequadas para produzir o licor. As etapas de seu processamento consistiram no preparo da matéria-prima (purê de banana), maceração alcoólica, trasfega e filtração, preparo do xarope, mistura, envelhecimento e envase.

Montou-se experimento fatorial $3 \times 2$ com 3 repetições: quantidade de banana $x$ teor alcoólico da solução extratora. As quantidades de banana foram 500, 800 e $1100 \mathrm{~g}$ para cada $4 \mathrm{~L}$ de licor pronto, correspondendo a $12,5 \%, 20,0 \%$ e $27,5 \%$ ( $/ \mathrm{v})$ de banana em relação ao produto final. A porcentagem de álcool na solução hidroalcoólica foi de 70 e $95 \pm 1 \%$ $(\mathrm{v} / \mathrm{v})$. Ajustou-se o licor preparado a partir desse extrato para conter teor alcoólico final de $18 \%(\mathrm{v} / \mathrm{v})$ e teor de açúcar final de $35 \%(\mathrm{p} / \mathrm{v})$. 
Visando padronizar o experimento foram mantidos constantes o volume da solução extratora em 1,1 L e o volume final do licor em $4 \mathrm{~L}$ para cada formulação (tratamento). Já o teor alcoólico da solução extratora e as quantidades de banana variaram, constituindo os diferentes tratamentos (Tabela 1).

\section{TABELA 1 - QUANTIDADE DE BANANA E TEOR ALCOÓLICO UTILIZADO NA MONTAGEM DOS DIFERENTES TRATAMENTOS}

\begin{tabular}{ccc}
\hline Tratamentos & $\begin{array}{c}\text { Quantidade de banana } \\
(\mathrm{g})\end{array}$ & $\begin{array}{c}\text { Teor alcoólico da solução extratora } \\
(\% \mathrm{v} / \mathrm{v})\end{array}$ \\
\hline 1 & 500 & 70 \\
2 & 800 & 70 \\
3 & 1100 & 70 \\
4 & 500 & 95 \\
5 & 800 & 95 \\
6 & 1100 & 95 \\
\hline
\end{tabular}

A solução extratora a $70 \%$ (v/v) foi preparada a partir de álcool de cereais a $95 \pm 1 \%$ $(\mathrm{v} / \mathrm{v})$.

Adotou-se o delineamento experimental inteiramente casualizado, montado em parcelas subdivididas de acordo com GOMES (2000). Nas parcelas foram alocados os tratamentos decorrentes da composição fatorial e nas subparcelas a variável tempo de extração. O experimento foi realizado com três repetições, sendo as amostras coletadas nos tempos de 1, 6, 11, 16 e 21 dias de extração. Durante o tempo de extração foram realizadas análises de $\mathrm{pH}$, acidez, cor, teor de sólidos solúveis e densidade a $20^{\circ} \mathrm{C}$. No extrato alcoólico pronto, ou seja, após os 21 dias de extração foram feitas as análises de $\mathrm{pH}$, acidez, cor, densidade a $20^{\circ} \mathrm{C}$, teor de sólidos solúveis e teor alcoólico. No licor jovem (tempo zero) efetuaram-se as análises de $\mathrm{pH}$, acidez, cor, densidade a $20^{\circ} \mathrm{C}$, teor de sólidos solúveis, viscosidade e teor alcoólico.

As análises de acidez titulável foram realizadas de acordo com as normas analíticas do IAL (1985).

Mediu-se o pH diretamente em pHmetro digital, marca Marconi, utilizandose $15 \mathrm{~mL}$ de amostra.

O teor de sólidos solúveis foi determinado diretamente em refratômetro manual e o resultado expresso em ${ }^{\circ}$ Brix. 
Avaliaram-se as coordenadas de cor eletronicamente, utilizando colorímetro modelo color Quest II Spera ("Hunter Lab Rest"), conectado a computador provido de sistema "software" universal. As amostras foram lidas diretamente no aparelho no modo refractância, utilizando-se a escala $L^{*}, a^{*}, b^{*}$ (CIELAB) em que $L^{*}$ é a luminosidade, $a^{*}$ a intensidade do vermelho/verde e $b^{*}$ a intensidade do amarelo/azul.

Mediu-se a densidade em picnômetro de $25 \mathrm{~mL}$, provido com termômetro, balança analítica com 4 casas decimais e banho de gelo para controle da temperatura.

Determinou-se a viscosidade cinemática em viscosímetro capilar de rotinas (Cannon-Fenske) marca SCHOTT-GERATE, Hofheim. Utilizouse o capilar $n^{\circ} 51320 / 200$, escolhido por meio de procedimentos recomendados pelo fabricante. Mediu-se o tempo de escoamento do fluido, sendo a viscosidade calculada conforme a equação 1 :

$$
v=K . t \text { (equação 1) }
$$

Em que:

$v=$ viscosidade cinemática;

$\mathrm{K}=$ constante do capilar usado ( $\left.\mathrm{n}^{\circ} 51320 / 200\right), \mathrm{K}=0,08992 \mathrm{~mm}^{2} / \mathrm{s}^{2}$;

$\mathrm{t}=$ tempo de escoamento.

Manteve-se a temperatura a $20 \pm 0,5^{\circ} \mathrm{C}$ com o auxílio de banho de água gelada. Obteve-se a viscosidade dinâmica multiplicando a viscosidade cinemática a $20^{\circ} \mathrm{C}$ pela densidade também a $20^{\circ} \mathrm{C}$.

O teor alcoólico foi medido pelo método da AOAC (1997) adaptado, que consiste em destilar dado volume da amostra e medir a densidade do destilado a $20 \pm 0,2^{\circ} \mathrm{C}$ com o auxílio de picnômetro.

Efetuaram-se testes sensoriais de aceitação para as amostras dos 6 tratamentos, após $45 \pm 5$ dias de armazenamento do licor, usando-se 70 julgadores não-treinados. Os atributos sabor alcoólico e impressão global foram avaliados mediante escala hedônica de 9 pontos, na qual o valor 1 corresponde a "desgostei extremamente" e o valor 9 a "gostei extremamente". As amostras foram servidas individualmente em copos descartáveis de $50 \mathrm{~mL}$ nas cabines individuais do laboratório de análises sensorial. Codificou-se cada amostra com 3 algarismos, escolhidos aleatoriamente, seguindo-se ordem de apresentação sorteada (CHAVES,1998; CHAVES e SPROESSER, 1999). 
Dois licores comerciais de frutas, sabores Kiwi e tangerina da marca STOKE, foram adquiridos e analisados quanto ao $\mathrm{pH}$, teor de sólidos solúveis e viscosidade para fins de comparação com os dados obtidos para o licor de banana.

\section{RESULTADOS E DISCUSSÃO}

A utilização do purê de banana mostrou-se vantajosa, pois é mais fácil manipular e pesar pasta homogênia do que trabalhar com rodelas de banana como ocorre no processo artesanal. Outra vantagem da utilização do purê de banana reside no fato de que o tratamento enzimático efetuado na sua preparação impediu o escurecimento excessivo da polpa de banana. Durante a adição da solução hidroalcoólica na polpa de banana foi necessário promover agitação, caso contrário haveria formação de grumos em virtude do alto poder desidratante do álcool. Tal agitação garantiu perfeita dispersão da polpa de banana, formando uma espécie de flocos e facilitando a extração dos componentes de interesse pelo aumento da superfície de contato. A relação polpa/casca de 1,68 ficou próxima de 1,74, citada por MATSUURA E FOLEGATTF (2001). As bananas utilizadas estavam bem maduras, com coloração da casca no ultimo estágio de maturação, equivalente ao escore 7 de classificação da CEAGESP (2003). A Tabela 2 ilustra a caracterização físico-química do purê de banana.

\section{TABELA 2 - COMPOSIÇÃO FÍSICO-QUÍMICA DO PURÊ DE BANANA}

\begin{tabular}{ccc}
\hline Tratamentos & $\begin{array}{c}\text { Quantidade de banana } \\
(\mathrm{g})\end{array}$ & $\begin{array}{c}\text { Teor alcoólico da solução extratora } \\
(\% \mathrm{v} / \mathrm{v})\end{array}$ \\
\hline 1 & 500 & 70 \\
2 & 800 & 70 \\
3 & 1100 & 70 \\
4 & 500 & 95 \\
5 & 800 & 95 \\
6 & 1100 & 95 \\
\hline
\end{tabular}

O teor de umidade encontrado para o purê de banana $(70,1 \%)$ mostrouse ligeiramente inferior ao verificado por CANO-CHAUCA et al. (2002) para banana "in natura" (73,50 \%). Tal diferença deve-se ao tratamento térmico do purê e à conseqüente perda de água, que também se aplica ao teor de sólidos solúveis. Para essa variável MOTA, LAJOLO e 
CORDENUNSI (1997) encontraram o valor de 20,6 Brix, ligeiramente inferior ao do purê de banana.

A acidez do purê de banana $(1,14 \%)$ foi o dobro da citada em BANANA... (2000) para a banana nanica madura $(0,512 \%)$, devido ao processo de agitação utilizado no preparo do purê (descrito em materiais e métodos). Tal processo também pode explicar a diferença verificada entre o $\mathrm{pH}$ do purê $(3,46)$ e o obtido por CANO-CHAUCA et al. (2002) para a banana nanica "in natura" madura $(5,10)$.

Ao se plotar no gráfico os pontos para as coordenadas de cor (L, b), sólidos solúveis ( ${ }^{\circ}$ Brix), pH e densidade em função do tempo de extração $(1,6,11,16,21$ dias) foram verificadas pequenas variações (Figuras 1, 2 , $3,4,5)$.

FIGURA 1 - VARIAÇÃO DA COORDENADA DE COR (L*) DO EXTRATO CONFORME O TEMPO DE EXTRAÇÃO PARA OS DIFERENTES TRATAMENTOS

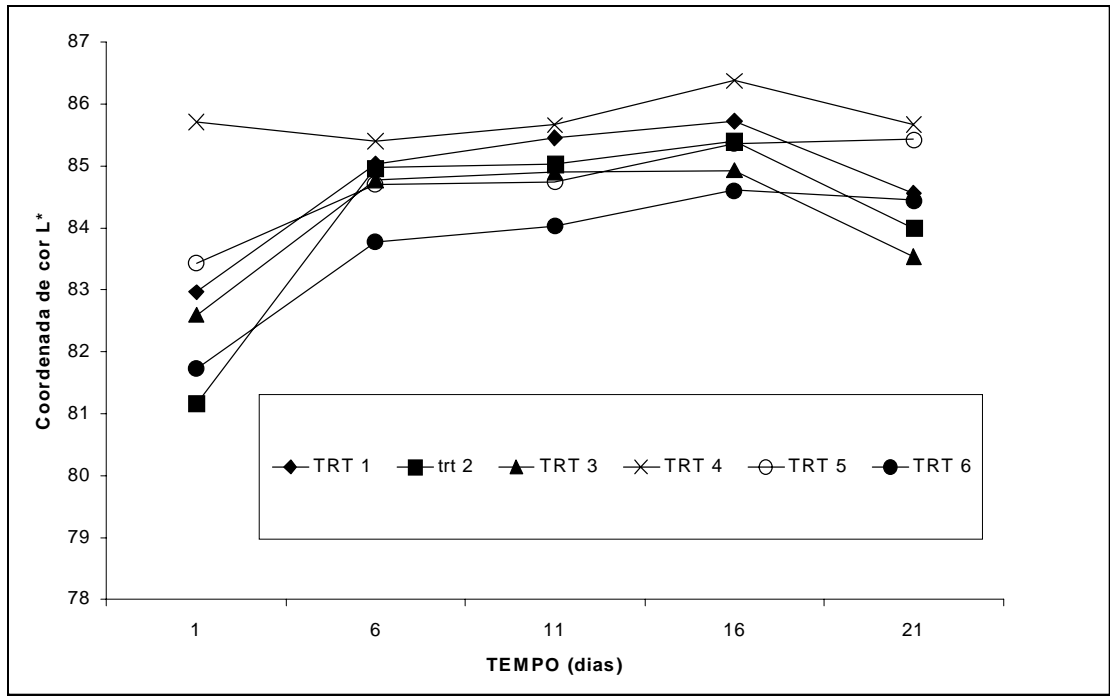

Para as mesmas quantidades de bananas, os tratamentos submetidos à extração em solução hidroalcoólica com maior concentração de álcool apresentaram maiores valores (basta contrastar os tratamentos $1 * 4 ; 2 * 5$ e $3^{*} 6$ ). Para todos os tratamentos, o valor de $L^{*}$ foi ascendente até 0 tempo de 16 dias e depois declinou. A densidade aumentou a partir de 
16 dias (Figura 5), provavelmente devido à extração de açúcares da banana. Esses por sua vez ofuscaram a luminosidade, contribuindo para a queda do valor de $L^{*}$. Sob o ponto de vista da luminosidade, a extração ideal duraria 16 dias.

\section{FIGURA 2 - VARIAÇÃO DA COORDENADA DE COR B* DO EXTRATO EM FUNÇÃO DO TEMPO DE EXTRAÇÃO PARA OS DIFERENTES TRATAMENTOS}

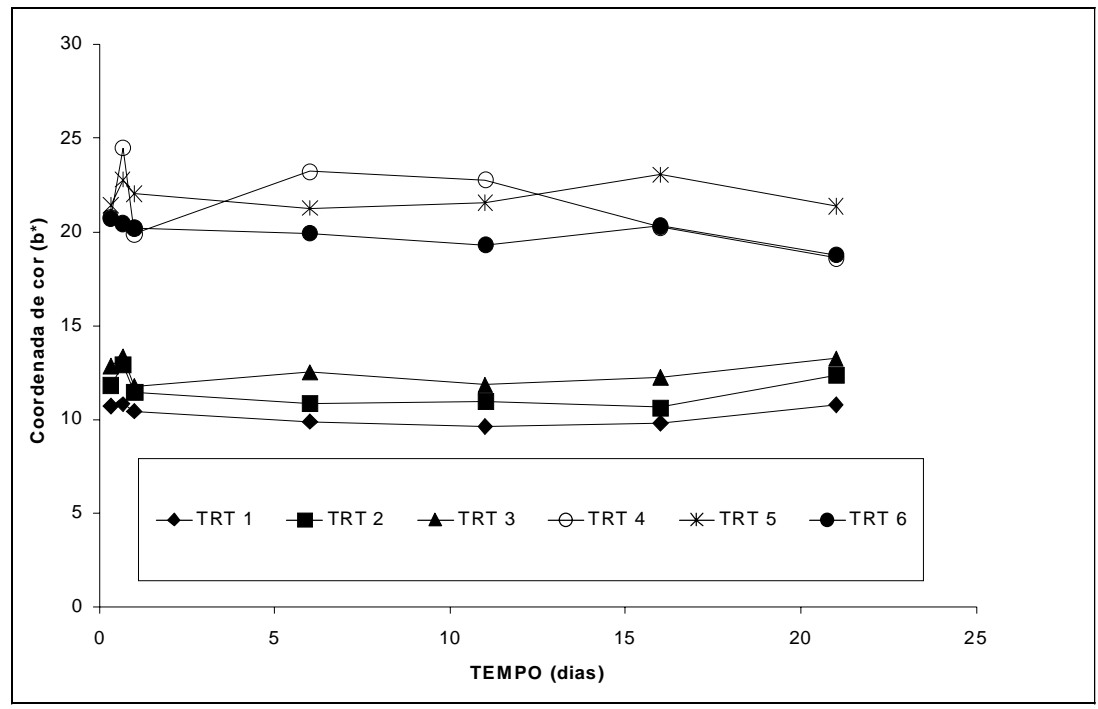

Verificou-se grande diferença entre os tratamentos com solução extratora a $70^{\circ} \mathrm{GL}$ e com solução extratora a $95^{\circ} \mathrm{GL}$. Os valores da coordenada de cor $b^{*}$ foram maiores para o grupo submetido à solução extratora com maior concentração em álcool. Isto se deve ao fato de que os pigmentos são mais solúveis em álcool do que em água. Os valores foram proporcionais no que se refere à quantidade de banana, ou seja, quanto maior a quantidade de banana maior o valor de $b^{*}$. Para o tempo de extração, o ponto máximo para a coordenada de cor b* do grupo a $95^{\circ} \mathrm{GL}$ ocorreu aos 16 dias. Já no outro grupo a extração foi mais lenta e não atingiu o ponto máximo no intervalo de 21 dias, embora tenha apresentado tendência de estagnação. 
FIGURA 3 - VARIAÇÃO DA CONCENTRAÇÃO DE SÓLIDOS SOLÚVEIS ('BRIX) NO EXTRATO HIDROALCOÓLICO EM FUNÇÃO DO TEMPO DE EXTRAÇÃO PARA OS DIFERENTES TRATAMENTOS

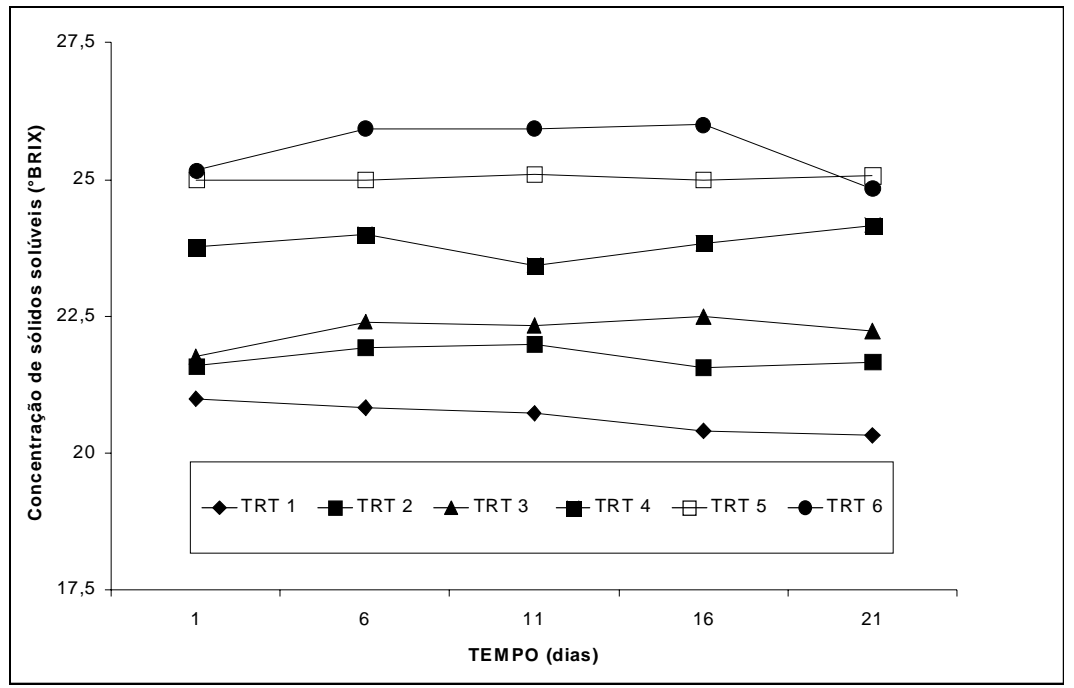

O valor de sólidos solúveis ( ${ }^{\circ}$ Brix) permaneceu praticamente inalterado para cada tratamento, indicando sua grande taxa de difusão. Assim, no que se refere a esse parâmetro a extração ocorreu nos primeiros dias e os valores de sólidos solúveis foram proporcionais à quantidade de banana.

FIGURA 4 - VARIAÇÃO DO PH DO EXTRATO DOS DIFERENTES TRATAMENTOS EM FUNÇÃO DO TEMPO DE EXTRAÇÃO

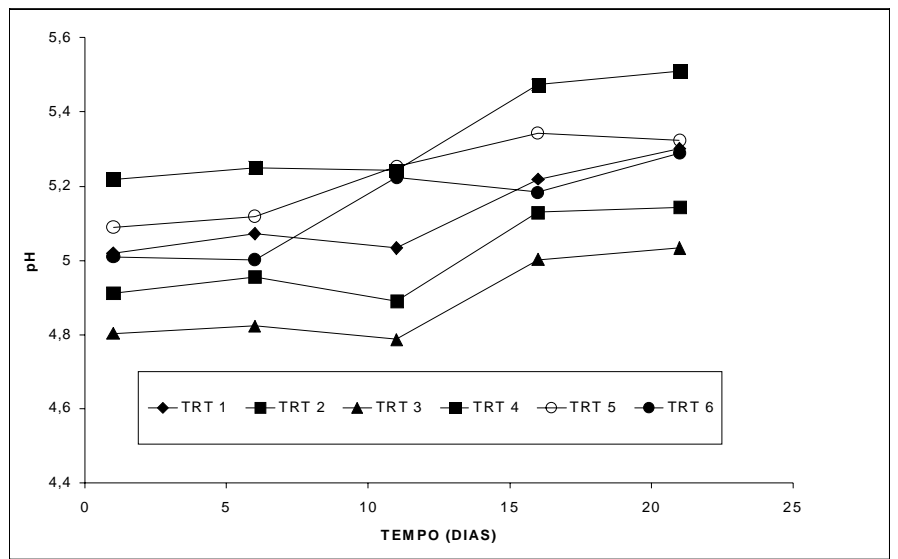


O teor alcoólico da solução extratora influenciou o valor do Brix obtido após extração, uma vez que os sólidos solúveis apresentam solubilidades diferentes dependendo da composição da solução extratora.

Os tratamentos do grupo $1\left(70{ }^{\circ} \mathrm{GL}\right)$ apresentaram $\mathrm{pH}$ menor do que os tratamentos do grupo $2\left(95^{\circ} \mathrm{GL}\right)$, evidenciando que os ácidos são mais solúveis em água do que em álcool. Todos os tratamentos revelaram tendência de estabilização após 16 dias de extração.

\section{FIGURA 5 - VARIAÇÃO DA DENSIDADE DO EXTRATO DOS DIFERENTES TRATAMENTOS EM FUNÇÃO DO TEMPO DE EXTRAÇÃO}

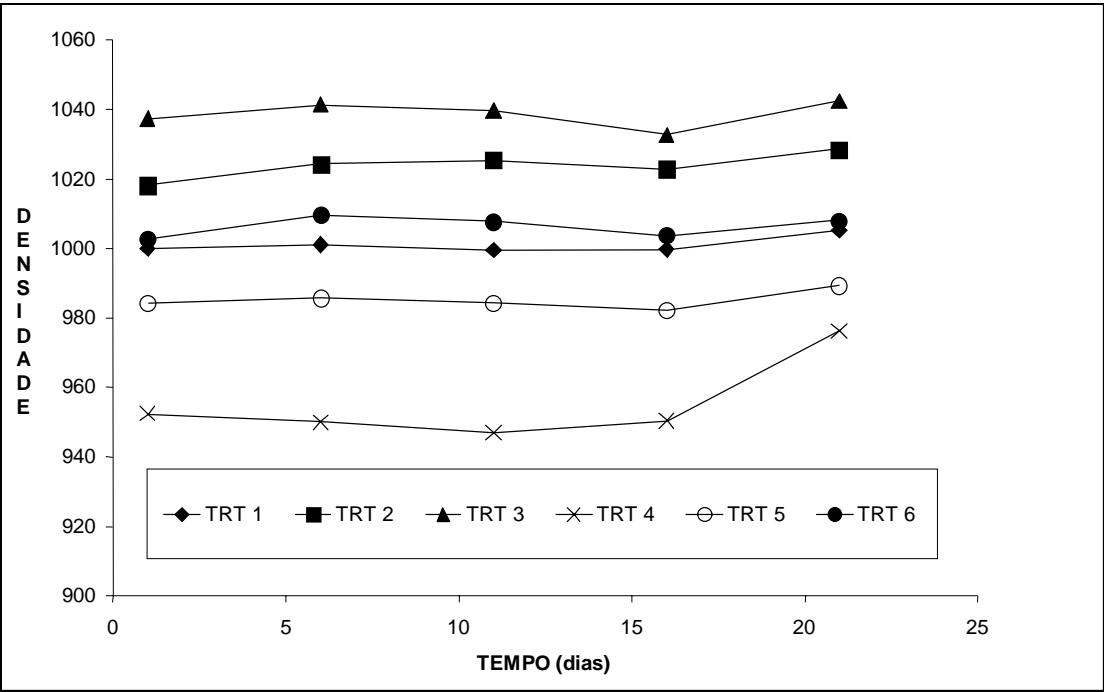

A densidade mostrou-se menor no grupo $2\left(95^{\circ} \mathrm{GL}\right)$ devido ao fato dos açúcares serem menos solúveis em álcool do que em água. A densidade foi proporcional à quantidade de banana utilizada. No que se refere ao tempo de extração, os valores permaneceram praticamente constantes até $016^{\circ}$ dia indicando que o equilíbrio ocorre rapidamente. Do dia 16 ao dia 21 houve pequeno aumento na densidade, provavelmente pelas variações de temperatura que influem na solubilidade dos sólidos solúveis presentes na solução hidroalcoólica. Portanto, a temperatura ambiente em que os extratores estão armazenados pode interferir na densidade do extrato obtido. 
A Tabela 3 mostra os resultados da análise de variância da regressão do teor alcoólico no extrato em função da quantidade de banana para cada concentração de solução extratora utilizada.

\section{TABELA 3 - RESUMO DA ANÁLISE DE VARIÂNCIA DA REGRESSÃO PARA A VARIÁVEL TEOR ALCOÓLICO DO EXTRATO (TE) EM FUNÇÃO DA QUANTIDADE DE BANANA (QB) E DO TEOR ALCOÓLICO DA SOLUÇÃO EXTRATORA (TA)}

\begin{tabular}{lcccc}
\hline FV & GL & SQ & QM & F \\
\hline Regressão & 2 & 1504.0805 & 752,0402 & 775,60 * \\
Falta de ajuste & 3 & 2.9645 & 0,9881 & 1,02 n.s. \\
(Tratamentos) & $(5)$ & $(1507.0450)$ & & \\
Resíduo & 13 & 11,5800 & 0,9650 & \\
\hline
\end{tabular}

* significativo ao nível de $5 \%$ de probabilidade pelo teste $\mathrm{F}$.

n.s = não-significativo ao nível de $5 \%$ de probabilidade pelo teste $\mathrm{F}$.

$\mathrm{GL}=$ Graus de liberdade.

$S Q=$ Soma de quadrados.

$\mathrm{QM}=$ Quadrado médio.

Como a regressão foi significativa e a falta de ajuste não-significativa, o modelo explicou significativamente a variação do teor alcoólico no extrato final em função da variação da quantidade de banana e do teor alcoólico da solução extratora. Além disso, obteve-se alto valor para r2 $(0,99)$. A Tabela 4 ilustra o resumo da análise para o teste de significância dos coeficientes da regressão.

\section{TABELA 4 - COEFICIENTES DA REGRESSÃO PARA O TEOR ALCOÓLICO DO EXTRATO EM FUNÇÃO DOS DIFERENTES TRATAMENTOS APLICADOS}

\begin{tabular}{lccc}
\hline $\mathrm{FV}$ & $\mathrm{GL}$ & Valor & $\operatorname{Pr}(\mathrm{t})$ \\
\hline $\mathrm{B}_{0}$ & 1 & 3,3400 & $0,071^{*}$ \\
$\mathrm{~B}_{1}$ & 1 & $-0,0146$ & $<0,0001^{*}$ \\
$\mathrm{~B}_{2}$ & 1 & 0,6724 & $<0,0001^{*}$ \\
\hline
\end{tabular}

* significativo ao nível de $7 \%$ de probabilidade pelo teste t. 
Conforme ilustrado nas Tabelas (3 e 4), a regressão e seus coeficientes são significativos e a falta de ajuste não-significativa, portanto a equação de regressão ajustada é significativa ao nível de $7 \%$ de probabilidade e está ilustrada na Equação 2:

$$
\mathrm{TE}=\text { 3,34 -0,0146QB + 0,6724 TA (Equação 2) }
$$

\section{Em que:}

TE = teor alcoólico $\left({ }^{\circ} \mathrm{GL}\right)$ do extrato após 21 dias de extração;

$\mathrm{QB}=$ quantidade de banana $(\mathrm{g})$ utilizada em cada tratamento:

$\mathrm{TA}=$ teor alcoólico $\left({ }^{\circ} \mathrm{GL}\right)$ da solução extratora.

A Figura 6 ilustra o gráfico obtido com os valores da equação de regressão ajustada.

\section{FIGURA 6 - TEOR ALCOÓLICO DO EXTRATO EM FUNÇÃO DOS DIFERENTES TRATAMENTOS}

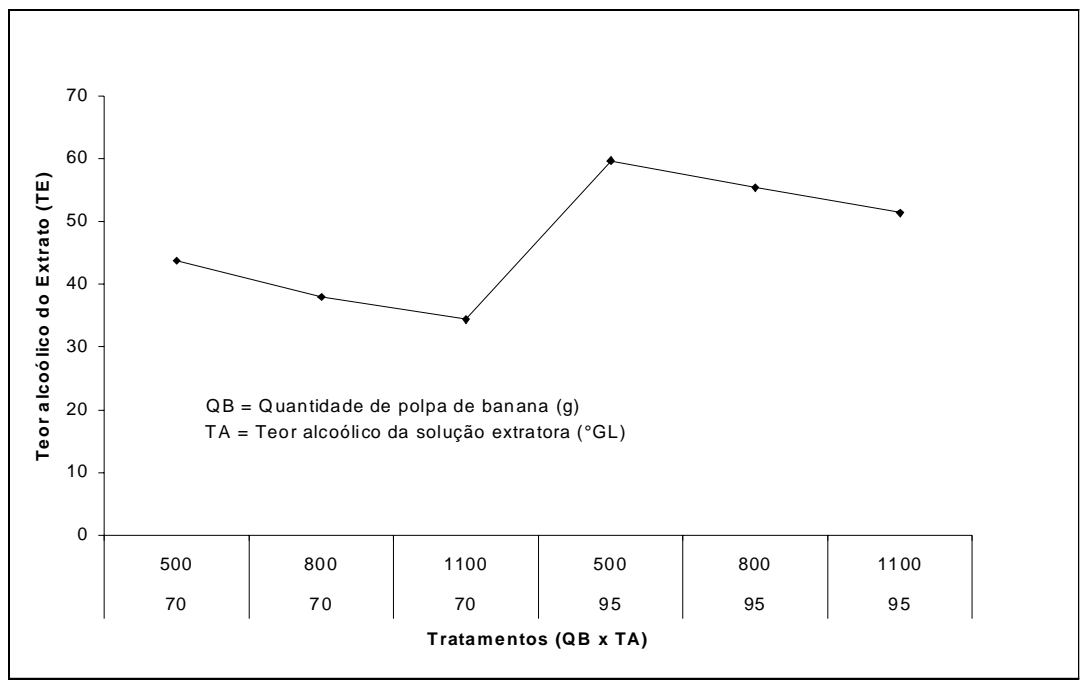

A quantidade de banana influenciou de forma inversa o teor alcoólico final (quanto mais banana maior a quantidade de torta de banana e a retenção de álcool, o que diminuiu o teor alcoólico final do extrato). Isto ocorre em função da relação volume de solução extratora/quantidade de banana diminuir com o aumento na quantidade de banana. Para melhorar 
o aproveitamento do álcool recomenda-se manter a relação solução/ quantidade de banana constante.

\subsection{CARACTERIZAÇÃO DO LICOR}

As análises físico-químicas realizadas no licor no tempo zero estão apresentadas na Tabela 5.

\section{TABELA 5 - CARACTERIZAÇÃO FÍSICO-QUÍMICA DO LICOR DE BANANA NO TEMPO ZERO}

\begin{tabular}{ccccccc}
\hline TRT & TA & $\begin{array}{c}\text { Acidez } \\
(\mathrm{mg} / 100 \mathrm{~mL})\end{array}$ & $\begin{array}{c}\text { Viscosidade } \\
\mathrm{mPa} . \mathrm{s}\end{array}$ & $\mathrm{pH}$ & $\begin{array}{c}\text { Sólidos solúveis } \\
\left({ }^{\circ} \text { Brix }\right)\end{array}$ & $\begin{array}{c}\text { Densidade } \\
\left(\mathrm{kg} / \mathrm{m}^{3}\right)\end{array}$ \\
\hline 1 & 18,20 & 59,67 & 7,25 & 4,78 & 36,00 & 1157,29 \\
2 & 17,87 & 86,94 & 10,00 & 4,78 & 40,50 & 1171,31 \\
3 & 17,83 & 109,52 & 10,92 & 4,78 & 39,67 & 1173,59 \\
4 & 18,77 & 57,89 & 10,47 & 4,79 & 39,67 & 1172,00 \\
5 & 17,83 & 88,06 & 10,58 & 4,73 & 39,67 & 1174,46 \\
6 & 17,80 & 106,16 & 11,12 & 4,72 & 40,67 & 1178,58 \\
\hline
\end{tabular}

Os valores referem-se à média de três repetições.

TRT $=$ Tratamentos (montados conforme descrito na Tabela 1).

TA = Teor alcoólico.

Acidez em mg de ácido málico por $100 \mathrm{~mL}$ de licor.

* Viscosidade dinâmica.

Segundo PENHA (2000), os julgadores em análise sensorial não conseguem distinguir o sabor de licores com variação de apenas $1^{\circ} \mathrm{GL} e$ neste trabalho a variação foi inferior $a \pm 0,20^{\circ} \mathrm{GL}$.

A viscosidade dinâmica é importante para o dimensionamento de bombas e filtros, estando relacionada com a aceitação sensorial. Alguns julgadores consideraram baixa a viscosidade (consistência) do licor. Os valores encontrados foram comparados com a viscosidade de dois licores de frutas (Kiwi e tangerina) da marca STOKE (5,55 e 9,43 mPa.s). Com exceção do tratamento 1 (TRT1), todos os demais apresentaram viscosidades superiores aos licores comerciais.

A acidez mostrou-se proporcional à quantidade de banana. $\mathrm{O} p H$ apresentou pouca variação, provavelmente devido à presença de ácidos orgânicos fracos e sais na composição do licor gerando poder tamponante. Os licores comerciais de Kiwi e Tangerina $(3,30$ e 3,60) apresentam pH inferiores ao do licor de banana. PENHA (2000) encontrou pH de 3,66 para o licor de acerola, fruta bastante ácida. 
Nos licores artesanais não há correção do teor de acidez, tendo sido encontrado o maior valor para o Tratamento 6 (aproximadamente $0,1 \%$ ).

O valor de sólidos solúveis (expresso em ${ }^{\circ}$ Brix) revelou-se praticamente constante e próximo a $40^{\circ} \mathrm{Brix}$. Os licores comerciais de tangerina e Kiwi apresentaram valores de sólidos solúveis de $32^{\circ}$ Brix e $39^{\circ}$ Brix respectivamente. MAGNANI, PÓVOA e MINIONI (1991) encontraram $33^{\circ}$ Brix para o licor de pêssego. A legislação permite extensa faixa de utilização de açúcar, que varia de no mínimo $100 \mathrm{~g} / \mathrm{L}$ até a saturação em açúcar. Apesar disso, os valores obtidos ficaram relativamente próximos dos encontrados pelos autores citados.

A densidade é proporcional aos teores de sólidos solúveis, uma vez que os componentes álcool e açúcar estão na mesma proporção.

O atributo cor é extremamente importante para a aceitação de determinados produtos pelo consumidor. A Tabela 6 permite analisar a modificação da cor nas diferentes etapas do processamento de licor.

\section{TABELA 6 - CARACTERÍSTICAS DAS COORDENADAS DE COR DO LICOR DE BANANA E DO EXTRATO}

\begin{tabular}{|c|c|c|c|c|c|c|}
\hline \multirow[b]{2}{*}{ TRT } & \multicolumn{3}{|c|}{ Licor de banana após preparo } & \multicolumn{3}{|c|}{ Extrato alcoólico após extração } \\
\hline & $\overline{\mathrm{L}^{*}}$ & $a^{*}$ & $b^{*}$ & $\mathrm{~L}^{*}$ & $A^{*}$ & $b^{*}$ \\
\hline 1 & 85,58 & 1,30 & 9,23 & 84,56 & 1,49 & $\overline{10,81}$ \\
\hline 2 & 85,26 & 1,52 & 10,19 & 83,99 & 1,98 & 12,40 \\
\hline 3 & 84,96 & 1,73 & 10,85 & 83,54 & 2,29 & 13,26 \\
\hline 4 & 81,69 & 2,42 & 15,00 & 85,68 & 1,20 & 18,63 \\
\hline 5 & 84,13 & 2,14 & 14,97 & 85,43 & 1,81 & 21,39 \\
\hline 6 & 83,91 & 2,19 & 14,40 & 84,44 & 1,90 & 18,78 \\
\hline Xarope $35^{\mathrm{a}}$ & 84,32 & 1,08 & 6,92 & $\mathrm{x}$ & $x$ & $\mathrm{X}$ \\
\hline Xarope $(18 ; 35)^{b}$ & 85,19 & 1,03 & 6,44 & $\mathrm{X}$ & $\mathrm{x}$ & $\mathrm{X}$ \\
\hline
\end{tabular}

TRT $=$ tratamento.

a = xarope de açúcar contendo $350 \mathrm{~g}$ de açúcar/L.

$\mathrm{b}=$ xarope de açúcar contendo $350 \mathrm{~g}$ de açúcar $/ \mathrm{L}$ e $18^{\circ} \mathrm{GL}$ em álcool.

Verificou-se que a cor final do licor sofre maior influência dos componentes extraídos da banana do que do álcool e do xarope de açúcar, ou da combinação de ambos.

\subsection{TESTE DE ACEITAÇÃO DO LICOR DE BANANA}

Como os tratamentos são quantitativos dever-se-ia realizar a análise de 
regressão, contudo os valores muitos próximos dos dados não permitiram ajustá-los a nenhum modelo. Assim, efetuou-se apenas a análise descritiva dos dados (Figura 7).

\section{FIGURA 7 - VARIAÇÃO DO ESCORE OBTIDO NO TESTE DE ACEITAÇÃO DO LICOR DE BANANA EM FUNÇÃO DOS DIFERENTES TRATAMENTOS}

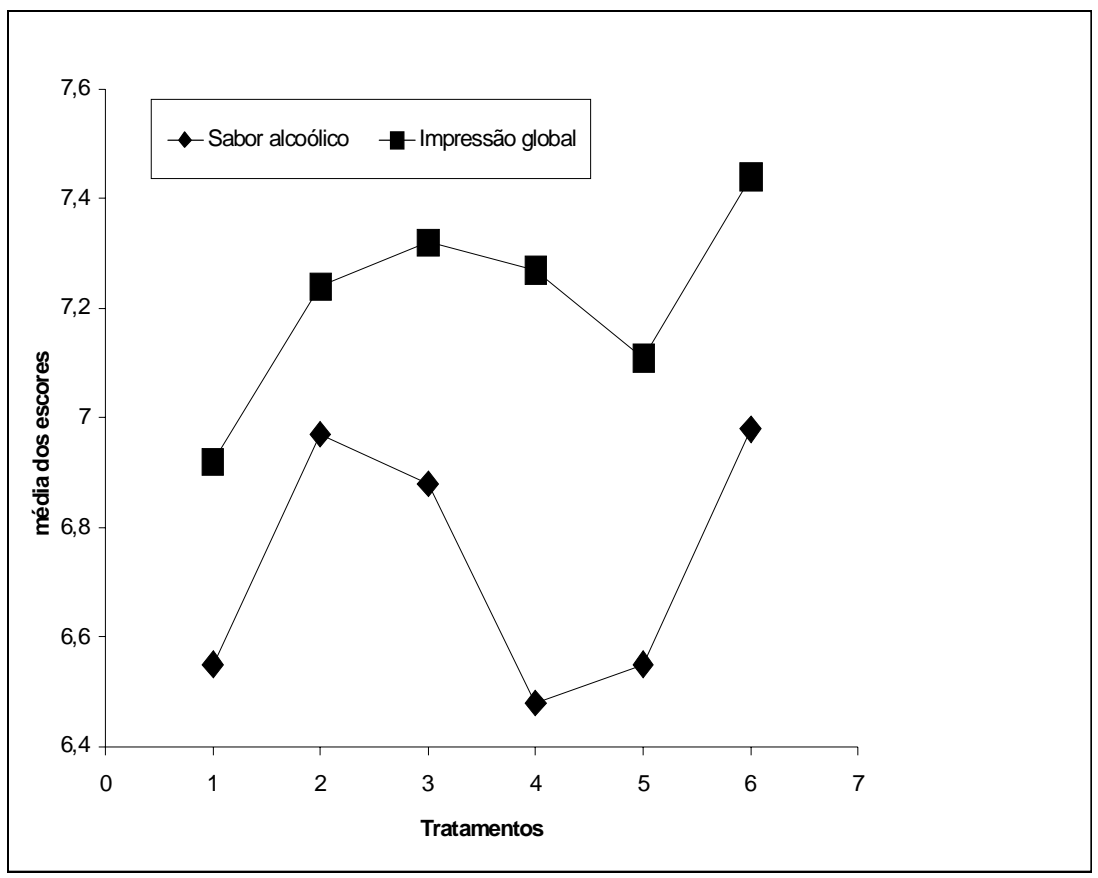

O escore obtido no teste de aceitação foi proporcional à quantidade de banana empregada. Analisando os três primeiros tratamentos verifica-se que a curva de impressão global tende a estagnar para o tratamento 3 , indicando que aumento na quantidade de banana além desse valor não melhoraria a sua aceitação por parte dos julgadores. Os tratamentos em que foi utilizada solução extratora com maior teor alcoólico obtiveram melhor aceitação. Nota-se pelo gráfico apresentado na Figura 2 que para esses tratamentos a coordenada de cor amarela $\left(b^{*}\right)$ foi mais intensa, podendo ter influenciado a melhor aceitação por parte dos julgadores. 


\title{
4 CONCLUSÃO
}

O tempo de 16 dias mostrou-se suficiente para finalizar a etapa de extração, evidenciando que o tempo de infusão deve ser de 15 a 16 dias. A solução extratora com teor alcoólico de $95^{\circ} \mathrm{GL}$ apresentou melhores resultados, principalmente no que se refere à cor final do produto e facilidade na filtração. Como não houve diferença significativa entre as quantidades de polpa de banana optou-se pela menor proporção em razão de fatores econômicos. Portanto, a utilização de $500 \mathrm{~g}$ de polpa de banana é suficiente para produzir $4 \mathrm{~L}$ de licor.

\begin{abstract}
TECHNOLOGICAL EVALUATION OF ALCOHOLIC EXTRACTION IN THE PROCESSING OF BANANA LIQUEUR

It was aimed at this work to establish the proportion of banana, the extract solution composition, as well as the extraction period to produce quality liqueur. A factorial experiment with three amounts of banana pulp (500,800 and $1100 \mathrm{~g}$ of banana to produce $4 \mathrm{~L}$ of liqueur) and, two alcoholic contents of the extraction solution (70 and $95^{\circ} \mathrm{GL}$ ) was used. The extraction process was studied during 21 days in which the color coordinates, the $\mathrm{pH}$, the soluble solids content and the density at $20{ }^{\circ} \mathrm{C}$ of the extract were analyzed. The immature liqueur was characterized, and a sensorial analysis after 45 days of aging was accomplished evidencing that the infusion period must be of 15 to 16 days. The extraction solution with alcoholic concentration of $95{ }^{\circ} \mathrm{GL}$ showed the best results, mainly on what is related to product final color and filtration easiness. As there wasn't significant differences among the amounts of banana pulp, the smallest proportion was chosen by economical reasons. Therefore, the utilization of $500 \mathrm{~g}$ of banana pulp is enough to produce $4 \mathrm{~L}$ of liqueur.
\end{abstract}

KEY-WORDS: BANANA LIQUEUR - PROCESSING, BANANA LIQUEUR - PHYSICALCHEMICAL ANALYSIS; SENSORY ANALYSIS.

\section{REFERÊNCIAS}

1 AQUARONE, E.; LIMA, U.A.; BORZANI, W. Alimentos e bebidas produzidos por fermentação. São Paulo: Edard Blucher, 1993. v.5. $227 \mathrm{p}$.

2 AOAC. Association of Official Analytical Chemists. Official methods of analysis of AOAC International. V.II. $16^{\text {th }}$ ed. Gaithersburg, 1997. v.2.

3 BANANA: cultura, matéria-prima, processamento e aspectos econômicos. Campinas: ITAL, 1995. 302 p. (Série Frutas Tropicais, 3). 
4 BORGES, J. M. Práticas de tecnologia de alimentos. Viçosa: Imprensa Universitária UFV, 1975. 156 p.

5 BRASIL. Decreto n. 2.314, de 4 de setembro de 1997. Regulamenta a lei $\mathrm{n}^{\circ} 8.918$ de 14 de julho de 1994, que dispõe sobre a padronização, a classificação, o registro, a inspeção, a produção e a fiscalização de bebidas. Diário Oficial [da] República Federativa do Brasil. Brasília, 5 set. 1997. Seção 1. p. $19549-19555$.

6 CEAGESP. Companhia de Armazéns Gerais do Estado de São Paulo. Normas para a classificação de frutas. Disponível em: www.ceagesp.com.br. Acesso em: 20 set. de 2003.

7 CANO-CHAUCA, M. N.; RAMOS, A.M.; STRINGHETA, P.C.; MINIM, V.P. Análisis físico-químico sensorial y microbiológico de la banana pasa. Alimentaria, n. 329, p. 119-122, fev. 2002.

8 CHAVES, J. B. P. Métodos de diferença em avaliação sensorial de alimentos e bebidas. Viçosa: UFV, 1998. 91 p.

9 CHAVES, J. B. P.; SPROESSER, R. L. Práticas de laboratório de análise sensorial de alimentos e bebidas. Viçosa: UFV, 1999. 81 p.

10 GOMES, F. P. Curso de estatística experimental. 14. ed. Piracicaba: Universidade de São Paulo, Escola Superior de Agricultura Luiz de Queiroz, 2000. 478 p.

11 HEBERT, G. Elaboration artesanal de licores. Zaragoza, Espana: Acribia, 1989. $117 \mathrm{p}$.

12 IAL. Instituto Adolfo Lutz. Normas analíticas do Instituto Adolfo Lutz: métodos químicos e físicos para análise de alimentos. 3 ed. São Paulo, 1985. 332 p. v.1.

13 MAGNANI, M. C.; PÓVOA, E.S.R.; MINIONI, E.C. Aproveitamento de resíduo industrial: fabricação de licor de caroços de pêssego. B. SBCTA, Campinas, v. 25, n. 2, p. 101-102, 1991.

14 MATSUURA, F.C.A; FOLEGATTF, M. I. S. (Ed.) Banana: pós-colheita. Brasília, DF: Embrapa Informação Tecnológica, 2001. 71 p. (Frutas do 
Brasil, 16).

15 MOTA, R.V.; LAJOLO, F.M.; CORDENUNSI, B.R. Composição em carboidratos de alguns cultivares de banana (Musa spp) durante o amadurecimento. Ciência e Tecnologia de Alimentos. v.17, n.2, p. 94-97, 1997.

16 PENHA, E. M. Produção de um licor de acerola. Campinas, 2000. 133 p. Tese (Doutorado em Ciência de Alimentos), Universidade Estadual de Campinas.

17 REVENTOS, P. El licorista en casa. Barcelona: SINTES, 1971. 112 p.

18 TRITTON, S.M. Spirits, aperitifs and liqueurs: their production. London: Faberand Faber, 1975. 82 p.

19 VARNAM, A.H.; SUTHERLAND, J.P. Beverages: technology, chemistry and microbiology. $2^{\text {nd }}$ London: Chapman \& Hall, 1994. 464 p. v. 2.

\section{AGRADECIMENTOS}

Ao CNPq e ao Departamento de Tecnologia de Alimentos da UFV. 